\title{
Modelling the long-term impacts of selective logging on genetic diversity and demographic structure of four tropical tree species in the Amazon forest
}

\author{
Alexandre M. Sebbenn ${ }^{\mathrm{a}, \mathrm{b}, *}$, Bernd Degen ${ }^{\mathrm{b}}$, Vânia C.R. Azevedo ${ }^{\mathrm{c}}$, Marivana B. Silva ${ }^{\mathrm{d}}$, \\ André E.B. de Lacerda ${ }^{\mathrm{e}}$, Ana Y. Ciampi ${ }^{\mathrm{c}}$, Milton Kanashiro ${ }^{\mathrm{e}}$, Francimary da S. Carneiro ${ }^{\mathrm{e}}$, \\ Ian Thompson ${ }^{\mathrm{e}}$, Marilyn D. Loveless ${ }^{\mathrm{f}}$ \\ ${ }^{a}$ Instituto Florestal de São Paulo, Estação Experimental de Tupi, Caixa Postal 339, 13400-970, Piracicaba, SP, Brazil \\ ${ }^{\mathrm{b}}$ Institut für Forstgenetik und Forstpflanzenzüchtung, Bundesforschungsanstalt für Forst- und Holzwirtschaft, \\ Sieker Landstrasse 2, D-22927 Grosshansdorf, Germany \\ ${ }^{\mathrm{c}}$ Embrapa Cenargen, C.P. 48, 66095-100, Brasília, DF, Brazil \\ ${ }^{\mathrm{d}}$ Universidade Federal do Pará, Campus Bragança, Rua Leandro Ribeiro s/n, Bairro Aldeia, CEP 68600-000, Bragança, PA, Brazil

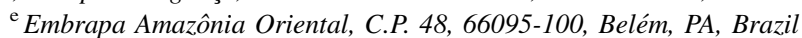 \\ ${ }_{\mathrm{f}}^{\mathrm{f}}$ Department of Biology, The College of Wooster, 931 College Mall, Wooster, OH 44691, USA \\ Received 8 February 2007; received in revised form 15 August 2007; accepted 16 August 2007
}

\begin{abstract}
In the last three decades, Amazon tropical forests have experienced high rates of deforestation, both by clearing for agriculture and by logging. In this study, we use computer simulations to examine the potential effects of forest logging on genetic diversity and demographic recovery (basal area development) of four neotropical tree species over a time frame reflecting multiple logging events. The study species, Bagassa guianensis Aubl., Hymenaea courbaril L., Manilkara huberi (Ducke) Chevalier, and Symphonia globulifera L.f., are all taxa which are commonly exploited for timber in the Brazilian Amazon. The simulations were parameterized using empirical data from field studies in the Tapajós National Forest, Pará State, Brazil, including genotypes at microsatellite loci, demography, ecology and growth for each species. Eight scenarios, combining two different cutting cycles and two minimum cutting diameters, were examined for each of the four species. The scenarios represent the actual forest practices used in Brazil and French Guiana (cutting diameter 45 and $60 \mathrm{~cm}$, and cutting cycle of 30 and 65 years, respectively). Logging scenarios were applied for six cutting cycles, and final genetic and demographic data were compared to baseline data from corresponding control scenarios. At the end of the simulated period the basal area was strongly reduced under all conditions in B. guianensis, H. courbaril, and M. huberi. In only two scenarios was a species able to recover its basal area following logging (S. globulifera with both 45- and 60-cm cutting diameters under a 65year cutting cycle). In the logging scenarios, all species showed a loss of alleles and genotypes and an increased genetic distance (calculated between each population at the start and the end of the simulations). These effects were higher under the most intensive logging cycles ( 30 years, $45 \mathrm{~cm}$ ). However, effective number of alleles, expected and observed heterozygosities, and the fixation index were little affected by the logging simulations. Over all, we conclude that, even under very optimistic conditions for growth and recruitment, current logging practices are not sustainable in terms of basal area. Our simulations show that different species respond differently to logging, both demographically and genetically. No single set of logging parameters can be applied to the forest as a whole. Rather, forest management practices must be species-specific, taking into account not only growth parameters but also ecological and reproductive variables, in order to move toward long-term forest sustainability. (C) 2007 Elsevier B.V. All rights reserved.
\end{abstract}

Keywords: Tropical forest; Computer simulations; Mating system; Genetic diversity; Logging practices; Forest growth rates; Sustainable forest management

* Corresponding author at: Instituto Florestal de São Paulo, Estação Experimental de Tupi, Caixa Postal 339, 13400-970, Piracicaba, SP, Brazil.

E-mail address: alexandresebbenn@yahoo.com.br (A.M. Sebbenn).

\section{Introduction}

Over the past three decades, the Amazon tropical forest has experienced high rates of deforestation, caused mainly by selective timber extraction and by conversion of forested land to agricultural crops or pasture (Asner et al., 2005). The impact of 
forest clearing for tropical tree species is obvious; populations in these sites are lost, and populations of species in adjacent, undamaged forest are more or less isolated into fragments of varying sizes. Selective logging is the primary timber production system in mixed tropical forest (Sist et al., 2003). Although forest cover remains after such logging practices, the selective removal of economically valuable trees and their genes may alter the genetic structure of the residual population, as well as affecting population density and diameter distribution, stand productivity, and ecosystem stability (Hawley et al., 2005). Genetic diversity provides the evolutionary potential for sustaining forest health in the face of biotic challenges and environmental changes (Mosseler et al., 2003). Therefore, conserving population structure and genetic diversity of tree species is crucial in protecting forested ecosystems (Mosseler et al., 2003; Rajora and Pluhar, 2003). Tree populations with reduced genetic diversity are more susceptible to environmental or disease-related reductions in productivity, fitness and health (Bergmann et al., 1990). Genetic structure can be altered by logging as a result of changes in gene frequency in the remaining individuals or disruptions of the mating system within populations at reduced, post-harvest densities (Rajora et al., 2000; Hawley et al., 2005). The genetic consequences of selective logging on genetic diversity and mating systems of forest tree species have been documented by both experimental and simulation studies (Murawski et al., 1994; Rajora and Pluhar, 2003; Glaubitz et al., 2003; Hawley et al., 2005; Degen et al., 2006). Understanding the ways in which species biology and logging practices interact is thus critical in making appropriate decisions about tropical forest management which will best contribute to longterm forest sustainability.

In general terms, selective cutting can have two principal effects on populations of tropical tree species: (a) reduction in the total number of reproductive individuals and (b) spatial isolation of remaining individuals. These effects can result in loss of alleles, reduction in heterozygosity (Young and Boyle, 2000), increase in selfing rate (Murawski et al., 1994; Obayashi et al., 2002; Ledig et al., 2005), correlated matings (Ledig et al., 2005), inbreeding and relatedness, alterations in the pollination neighbourhood area (Aldrich and Hamrick, 1998), and reduction in the effective size of the remaining population.

In general, most studies which have examined the effects of harvesting on genetic diversity have compared existing, unlogged populations with nearby, recently logged ones. This method has flaws, however, since it assumes that the two populations were initially identical. Comparisons of several logged populations with several unlogged population would make such studies more robust. But even so, such studies document the results of a particular logging event, and not the probable effects of logging processes over many successive cutting cycles. They provide measures of short-term effects, generally soon after a single cutting episode. However, most of the effects of forest logging are likely to be cumulative and complex, potentially generating progressive changes as logging continues. These effects are impossible to detect simply by comparing unlogged with recently logged populations, especially in Amazon forests where, in most cases, only a single cutting cycle has so far been done.

The paradigm for sustainable logging in the neotropics (and elsewhere) assumes that forests will be harvested repeatedly, on a pre-determined (and often economically driven) cycle. The underlying assumption is that forests and their component species will be resilient to these logging events, recovering in each interval to permit long-term, sustainable harvest of target species, although there are reasons to suspect that this will not be so. Such effects cannot be measured in real time, since the requisite systems do not exist. In order to infer the long-term impacts of logging or other land use changes, simulation models are required.

Eco-Gene was developed to study the short- and long-term effects of forest logging on genetic diversity and the demography of tree species (Degen et al., 1996, 2006). The model combines elements of population genetics, demographic dynamics, tree growth and forest management. Empirical data on the genotypes of individual trees, their spatial position and their diameter are used to initiate the simulations. This model has already been used to study the effects of air pollution, forest logging, and fragmentation on the genetic diversity of tree species (Degen and Scholz, 1998; Degen et al., 2002, 2006).

Here, we studied the long-term effects of forest logging on genetic diversity and demography of four tropical tree species [Bagassa guianensis Aubl. (Moraceae), Hymenaea courbaril L. (Leguminoseae), Manilkara huberi (Ducke) A. Chev. (Sapotaceae), and Symphonia globulifera L.f. (Clusiaceae)] occurring in the Tapajós National Forest, Pará State, Brazil. The scenarios were selected to allow a comparison of current forest management methods used or proposed for use in Brazil and French Guiana.

\section{Materials and methods}

\subsection{Study area}

The data on the species used for our simulations were collected by the Dendrogene project (EMBRAPA/DFID) in a 500 ha experimental plot in the Tapajós National Forest $\left(55^{\circ} 00^{\prime} \mathrm{W}, 2^{\circ} 45^{\prime} \mathrm{S}\right), 83 \mathrm{~km}$ south of Santarem, in the State of Pará, Brazil (Kanashiro et al., 2002). The Tapajós Forest is a typical terra firme rain forest. The area has a humid tropical climate (Ami under the Köppen system), with an annual rainfall of 1900-2110 mm, a rainy season from December to May, and mean monthly temperatures between 24 and $26^{\circ} \mathrm{C}$ throughout the year.

\subsection{Study species}

All four species are common elements of terra firme forests, some reaching heights of $40 \mathrm{~m}$ or more, and all are exploited for timber production in the Brazilian Amazon. They differ in their densities in the Tapajós forest, however. Manilkara is the most common of the four species, with a density in the study area of 3.35 trees $>10 \mathrm{~cm} \mathrm{dbh} /$ ha. Symphonia and Hymenaea are intermediate in density ( 0.83 and 0.54 trees, respectively, 
Table 1

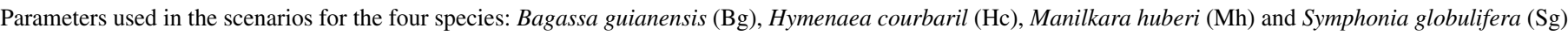

\begin{tabular}{|c|c|c|c|c|c|}
\hline No. & Parameter & $\mathrm{Bg}$ & $\mathrm{Hc}$ & Mh & $\mathrm{Sg}$ \\
\hline \multicolumn{6}{|l|}{ Growth } \\
\hline P1 & Mean growth rate $(\mathrm{cm} / \text { year })^{\mathrm{a}}$ & 0.35 & 0.40 & 0.37 & 0.42 \\
\hline $\mathrm{P} 2$ & Standard deviation growth (cm/year) & 0.31 & 0.33 & 0.25 & 0.28 \\
\hline P3 & Temporal autocorrelation growth & 0.43 & 0.55 & 0.61 & 0.53 \\
\hline $\mathrm{P} 4$ & Maximum diameter at the 95-percentile $(\mathrm{cm})$ & 139 & 154 & 140 & 80 \\
\hline \multicolumn{6}{|c|}{ Demography } \\
\hline P5 & Density diameter class $0-10(\mathrm{~N} / \mathrm{ha})$ & 0.08 & 0.20 & 7.13 & 0.65 \\
\hline P6 & Density diameter class $10-20(\mathrm{~N} / \mathrm{ha})$ & 0.08 & 0.20 & 0.81 & 0.50 \\
\hline P7 & Density diameter class 20-30 (N/ha) & 0.02 & 0.09 & 0.56 & 0.20 \\
\hline P8 & Density diameter class 30-40 (N/ha) & 0.02 & 0.09 & 0.35 & 0.16 \\
\hline P9 & Density diameter class $40-50(\mathrm{~N} / \mathrm{ha})$ & 0.02 & 0.07 & 0.34 & 0.05 \\
\hline P10 & Density diameter class 50-60 (N/ha) & 0.02 & 0.07 & 0.32 & 0.03 \\
\hline P11 & Density diameter class 60-70 (N/ha) & 0.02 & 0.07 & 0.21 & 0.01 \\
\hline $\mathrm{P} 12$ & Density diameter class 70-100 (N/ha) & 0.06 & 0.07 & 0.57 & 0.01 \\
\hline P13 & Density diameter class 100-150 (N/ha) & 0.05 & 0.06 & 0.19 & - \\
\hline \multicolumn{6}{|c|}{ Phenology } \\
\hline P14 & Percentage of flowering adults —-minimum & 80 & 48 & 10 & 84 \\
\hline P15 & Percentage of flowering adults-maximum & 95 & 90 & 85 & 94 \\
\hline P16 & Minimum diameter of flowering trees $(\mathrm{cm})$ & 42 & 49 & 35 & 20 \\
\hline $\mathrm{P} 17$ & Flowering rhythm (years/years) & $1 / 1$ & $1 / 1$ & $1 / 4$ & $1 / 1$ \\
\hline \multicolumn{6}{|c|}{ Pollination } \\
\hline P18 & Self-incompatibility-minimum & 1.0 & 0.9 & 0.85 & 0.85 \\
\hline P19 & Self-incompatibility-maximum & 1.0 & 1.0 & 1.0 & 1.0 \\
\hline $\mathrm{P} 20$ & Flight distance pollinator-maximum (m) & 2500 & 2500 & 800 & 800 \\
\hline $\mathrm{P} 21$ & Distance of random pollination (m) & 100 & 100 & 50 & 50 \\
\hline \multicolumn{6}{|c|}{ Seed dispersal } \\
\hline P22 & Proportion of wind dispersal & 0 & 0 & 0.7 & 0.1 \\
\hline $\mathrm{P} 23$ & Exponent for wind dispersal & 0 & 0 & 5 & 5 \\
\hline $\mathrm{P} 24$ & Proportion dispersal by small birds or bats & 1 & 0.3 & 0.3 & 0.4 \\
\hline $\mathrm{P} 25$ & Distance for random seed dispersal (m) & 2000 & 200 & 1000 & 400 \\
\hline $\mathrm{P} 26$ & Proportion of dispersal by large bats (roosts) & 0 & 0.7 & - & 0.5 \\
\hline $\mathrm{P} 27$ & Maximum flight distance to roosts (m) & 0 & 2500 & - & 2500 \\
\hline
\end{tabular}

a Silva et al. (1995, 1996) and Phillips et al. (2004).

$>10 \mathrm{~cm} \mathrm{dbh} / \mathrm{ha}$ ). The least common species is Bagassa, a longlived pioneer with only 0.20 trees $>10 \mathrm{~cm} \mathrm{dbh} / \mathrm{ha}$ in the Tapajós region. In addition, Bagassa is dioecious, which further reduces its effective density, from the perspective of pollen movement. Thus, Bagassa is completely outcrossed, while there is the potential for self-pollination in the other three, hermaphroditic species.

All four species are visited by insects, but some also have vertebrates as likely pollinators. Manilkara is probably completely insect-pollinated; visitors include Ornidia obesa, Eristalis sp., Apis mellifera, Mellipona malanoventer, Mellipona compressipes, Paratetrapedia spp., and Augochloropsis spp. (Maues, 2006). In addition to insect-pollination, Hymenaea is also reported as being bat-pollinated, and bats (Glossophaga soricina, Carollia perspicilata, Phyllostomus discolor, and Artibeus spp.; Maues, 2006) are floral visitors. Symphonia has been reported to have a diverse set of pollinators throughout its neotropical range. Lepidopterans were cited as its primary pollinator in Costa Rica (Pascarella, 1992), while perching birds (in French Guiana, Gill et al., 1998) and hummingbirds (in central Amazonia, Bittrich and Amaral, 1996) are reported to be the main pollinators. At our site, Symphonia is largely hummingbird-pollinated (Maues, 2001).
Although its floral morphology suggests that Bagassa is batpollinated, detailed investigations in our study area (Silva, 2005) show that thrips are also common on the flowers. In fact, pollination in Bagassa is probably wind, associated with thrips (Maues, 2006). The reproductive parameters in our model scenarios (Table 1) are chosen to reflect these different floral biologies and pollination syndromes.

All four species produce propagules adapted for animal dispersal. Hymenaea has large, few-seeded pods with an edible seed matrix, and may sometimes be dispersed long distances by vertebrates. However, most fruits are likely to fall beneath the tree, and to be taken only short distances by scatterhoarding vertebrates. Thus, we modelled its seed dispersal as a mixture of patterns, with $30 \%$ of seeds dispersed locally, in a random pattern within a radius of $200 \mathrm{~m}$, and $70 \%$ of fruits moving longer distances to clustered distributions (as to feeding roosts) up to $2500 \mathrm{~m}$ from the maternal tree. The other three species all produce smaller, fleshy or pulpy fruits, and for these species, dispersal was simulated as a combination of "wind" dispersal (local, negative exponential), small bird/bat dispersal (random), and dispersal to far-away roosts or defecation areas, as is typical of larger bats and birds (see Table 1 for details). 


\subsection{Sample size}

All individuals with $\mathrm{dbh} \geq 20 \mathrm{~cm}$ within the 500 ha study plot were mapped, measured for $\mathrm{dbh}$ and height, and genotyped at microsatellite loci. Additionally, a subplot of 100 ha was established for M. huberi and S. globulifera where individuals $\geq 10 \mathrm{~cm}$ were also mapped and genotyped. Ecological studies on flowering phenology, seedling recruitment and seed dispersal in unlogged forest were made for each species over a period of 2 years (Kanashiro et al., 2002).

Because of differences in density between species, the number of genotyped adult trees ranged from 92 (B. guianensis) to 300 (M. huberi). Genotypes at five to nine microsatellite loci were screened. The data were analyzed to estimate allele frequencies, fixation indices and spatial genetic structure among adults (Kanashiro et al., 2002). To estimate gene flow and mating systems, progeny arrays were collected from reproductive individuals. About 20-30 seeds were collected from 18 to 30 maternal individuals of each species in at least 1 year. Genetic analysis of progeny was used to measure outcrossing rates under a mixed mating system model (Ritland and Jain, 1981). Pollen dispersal distances were calculated for all species using TwoGener analysis (Smouse et al., 2001) and additionally for Bagassa, Hymenaea and Symphonia using paternity analysis (Marshall et al., 1998).

\subsection{Simulation model}

At the beginning of the simulation, input data and parameters are defined (Table 1). The dynamics of each species population is then simulated over a specified interval. Each simulated year include steps in which tree growth occurs, logging may or may not take place, adult individuals flower and are pollinated, seed genotypes are generated, seeds are dispersed, and individuals then experience mortality based on parameters defined in the model. Fig. 1 shows a flow chart of

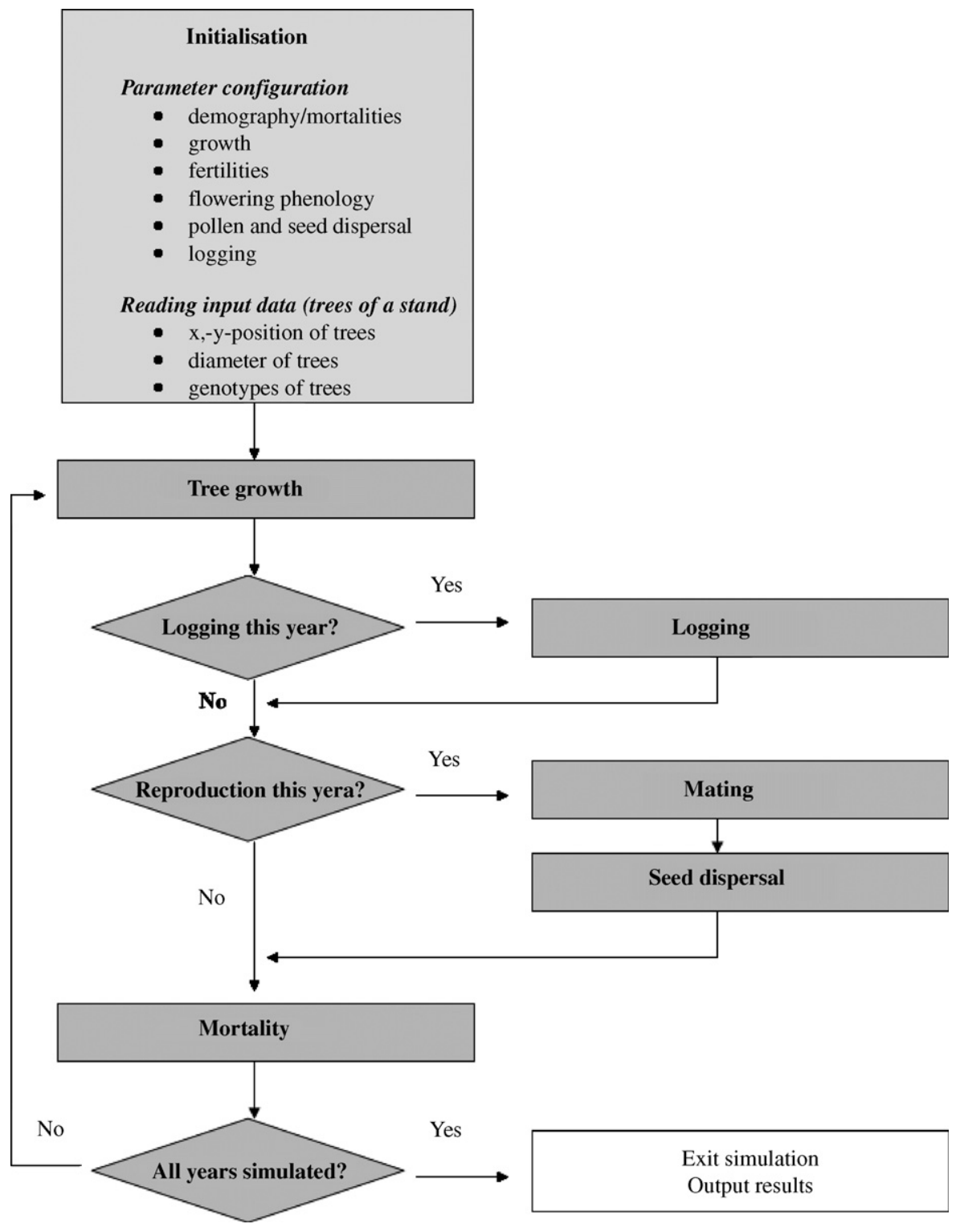

Fig. 1. Processes and factors integrated in Eco-Gene. 
the different steps and integrated processes of the simulations. For a detailed description of the model see Degen et al. (2006).

\subsection{Dataset}

The dataset used for the simulations was generated by a two-step process. The goal was to create a starting population for each species that accurately reflected its genetic and demographic characteristics at the study site in Tapajós. The original field inventories provided density and size class distributions for trees above $10 \mathrm{~cm} \mathrm{dbh}$, as well as an aggregation index, specifying the spatial clumping of individuals. The genetic information (allele frequencies, fixation index, and spatial autocorrelation at each locus) also came from the Tapajós populations. However, the inventories did not include juveniles ( $<10 \mathrm{~cm} \mathrm{dbh})$, which are required to simulate a real population over time. In addition, the differences in density among the four study species meant that population sizes within the study site (500 ha) were very different. To address these issues, we used a subprogram, the Data Generation Engine (Dendrobase), which takes aggregate descriptors, like those listed above, and generates a model population of a given size which matches the demographic and genetic parameters from the field. We used this to produce a model population of 300 adult (reproductive-sized) individuals for each species, in order to equalize population sizes and make final simulation results comparable among the species. Because of the differences in density, the simulated populations for each species occupied very different areas. For Bagassa, an area of 1869 ha was required to include 300 reproductive individuals. Corresponding areas for the other three species were 1296 ha for Symphonia, 1225 ha for Hymenaea, and 217 ha for Manilkara.

To generate the juvenile age classes, we entered this adult population into the Eco-Gene model, and ran it for 500 years (1300 years for Manilkara), with flowering, reproduction, and seed dispersal as parameterized from field data, until the population achieved a steady size. We determined the density and mortality parameters for juveniles from field data in the Tapajós, using transects to measure seedlings, samplings, and young tree densities. After 500 (1300) years, we then had a population in which all size classes were represented at densities which corresponded to field observations for this forest site. At that point, we calculated genetic parameters (fixation index, gene frequencies, and spatial autocorrelation patterns) and compared them to baseline field data. If they did not correspond to requisite parameters, we re-ran the model until the final population matched all the demographic and genetic descriptors of these species in the field site. These final composite populations were then used at the starting point for the logging scenario simulations (Table 2).

For Bagassa we used data from five microsatellite loci (Silva, 2005), for Hymenaea nine microsatellite loci (Lacerda, pers. commun.), for Manilkara data from eight microsatellite loci (Azevedo et al., 2005) and for Symphonia data on six microsatellite loci (Degen et al., 2004; Vison et al., 2005; Carneiro et al., 2007).
Table 2

Demographic and genetic parameters of the initial populations for the control and logging simulation scenarios of the four study species: B. guianensis $(\mathrm{Bg})$, H. courbaril $(\mathrm{Hc}), M$. huberi $(\mathrm{Mh})$ and $S$. globulifera $(\mathrm{Sg})$

\begin{tabular}{|c|c|c|c|c|}
\hline Parameter & $\mathrm{Bg}$ & $\mathrm{Hc}$ & $\mathrm{Mh}$ & $\mathrm{Sg}$ \\
\hline Population size & 490 & 525 & 963 & 599 \\
\hline Basal area $\left(\mathrm{m}^{2} / \mathrm{ha}\right)$ & 0.066 & 0.135 & 0.755 & 0.035 \\
\hline Number of alleles, $A$ & 32 & 183 & 122 & 141 \\
\hline $\begin{array}{l}\text { Effective number } \\
\text { of alleles, } A_{\mathrm{e}}\end{array}$ & 2.49 & 3.59 & 6.43 & 9.61 \\
\hline $\begin{array}{l}\text { Observed } \\
\quad \text { heterozygosity, } H_{\mathrm{o}}\end{array}$ & 0.643 & 0.563 & 0.731 & 0.807 \\
\hline Fixation index, $F$ & -0.069 & 0.220 & 0.134 & 0.098 \\
\hline $\begin{array}{l}\text { Number of single-locus } \\
\text { genotypes, NG }\end{array}$ & 88 & 829 & 675 & 843 \\
\hline
\end{tabular}

\subsection{Tree growth/tree densities}

In the initial runs and in the simulations, each species was assigned a species-specific growth function (Table 1) derived from measurements in a series of unlogged experimental plots at Jarí Cellulose and in the Tapajós National Forest areas over a 16-year period (Silva et al., 1995, 1996; Phillips et al., 2004).

\subsection{Reproduction}

Reproduction within the Eco-Gene simulation model includes parameters controlling the flowering phenology, differences in male and female fertilities, measures of incompatibility, and pollen and seed dispersal. Observations on flowering phenology in the Tapajós forest showed that populations of Bagassa, Hymenaea and Synphonia flower annually, while Manilkara flowers once every 3-5 years (Table 1). The proportion of plants flowering within a population varies between years and trees must reach a certain diameter to begin flowering. Collectively, these parameters define the overlap in flowering within the female and male flowering phase in each individual and among different individuals of a population. Hymenaea, Manilkara and Symphonia are hermaphroditic, and thus we assumed identical periods of male and female flowering within each tree. However, Bagassa is a dioecious species, so we modelled the occurrence of female and male trees by defining an additional locus controlling the sex of each tree (male genotype 11, female genotype 12). In the Tapajós plot, the sex ratio (M:F) of Bagassa adult trees was about 1:1 (Silva, 2005).

\subsection{Pollen dispersal and fertilities}

Based on experimental data, we set self-incompatibility rates at relatively high values (90\% for Hymenaea, $80 \%$ for Manilkara and Symphonia). Self-incompatibility was $100 \%$ for the dioecious Bagassa. For outcrossing events within the model, only trees with overlapping flowering periods can give rise to fruit set. Simulated pollinator flights that do not result in inter-tree pollen dispersal are eliminated based on pre-defined levels of self-incompatibility (Table 1). Seed production was simulated taking into account possible variation in male and 
female fertility among trees. Trees with higher female or male fertility have a proportionately higher probability of contributing their ovules or pollen to seeds. Each flowering tree was assigned a relative value for its fertility proportional to its dbh, and variation in individual and in gender-based fertility was simulated based on a normal distribution.

\subsection{Recruitment and mortality}

Recruitment of juveniles from seed was simulated based on the density and size class distribution for each species in unlogged forest in the Tapajos region. This observed diameter and frequency distribution was considered the absolute "target" for regeneration and for seedling and juvenile mortality. Based on this set of parameters, if there is sufficient reproduction in the post-logged population, it will return to this target diameter distribution. The model Eco-Gene calculates the probability of mortality from the ratio of actual densities (at the end of each reproduction and dispersal event) and these target densities.

\subsection{Scenarios}

In the logging scenarios, we examined two elements of logging practices: minimum cutting diameter and proposed cutting cycle. Our logging scenarios were chosen to represent combinations of the more intensive logging practices in the Brazilian Amazon (minimum cutting diameter of $45 \mathrm{~cm} \mathrm{dbh}$ and proposed cutting cycle of 30 years) and the more moderate logging practices in French Guiana (cutting diameter of $60 \mathrm{~cm}$ and a hypothetical cutting cycle of 65 years). For Hymenaea, however, our simulations used a minimum cutting diameter of $55 \mathrm{~cm}$ rather than $45 \mathrm{~cm}$, since our field data indicate that this species starts flowering only when it reaches a dbh of about $49 \mathrm{~cm}$. Thus, our simulations for logging of Hymenaea are more optimistic than is the usual case in the Amazon. Actual logging practice applies a $45 \mathrm{~cm}$ minimum cutting diameter for all logged species. Based on our observations of age at first reproduction, simulations run with a $45-\mathrm{cm}$ cutting diameter would have resulted in reproductive failure for this species.

It is important to note that, at this time, cutting cycles have not actually been implemented in harvesting neotropical forests, since timber exploitation, at least in the Amazon, has so far involved exploration of new, uncut forest rather than return cutting at previously harvested locations. Models of "sustainable forest extraction" propose such cutting cycles to generate continuous timber yields from these forests. Our simulations thus attempt to predict the potential long-term outcomes of extended cutting practices on the demographic and genetic makeup of species populations, using species-specific ecological traits and what, for the majority of species, are steady-state assumptions about species regeneration after logging. Harvesting rules attempt to mitigate the pressure of selective logging by requiring that $10 \%$ of harvestable trees are retained as seed trees and that hollow trees which are still reproductively active are left behind as seed sources.
For each of the four species, we simulated the long-term effects of pre-defined logging scenarios over six sequential cutting cycles. Starting populations grew and reproduced for 2 years before the first logging episode. Thereafter, populations were logged at specified intervals (30 or 65 years). In each case, the population was allowed to grow and recover for one more cutting interval after the sixth logging episode, and genetic and demographic parameters were then measured on that final population. Thus, for scenarios with a 30-year cutting cycle, the final parameters were measured after 182 years $(2+(6 \times 30)$ years $)$; a 65-year cutting cycle resulted in scenarios of 392 years $(2+(6 \times 65)$ years $)$. Within each cutting cycle, we simulated minimum cutting diameters of either $45 \mathrm{~cm}$ (55 for Hymenaea) or $60 \mathrm{~cm}$. Logging outcomes were compared to a corresponding unlogged control scenario run for the same total duration and with the same growth rate.

The model implements post-logging mortality in the year after each logging episode. In the simulation we assumed values for post-logging mortality based on estimates from Gourlet-Fleury et al. (2004). Mortality for trees from 0 to $10 \mathrm{~cm} \mathrm{dbh}$ was 0.20 ; for trees $10-20$ and $20-45 \mathrm{~cm} \mathrm{dbh}$, the corresponding values were 0.15 and 0.10 . Logging removed $90 \%$ of all trees above either $45(55) \mathrm{cm}$ dbh or above $60 \mathrm{~cm}$ dbh. In scenarios with a $60-\mathrm{cm}$ cutting limit, trees from 45 to $60 \mathrm{~cm}$ did not experience an elevated post-logging mortality. These harvesting mortalities were applied only in the year after logging, after which default mortalities were re-instituted until the next cut.

The Eco-Gene model has stochastic elements which come into play in the various life stages in each year and over the course of each run. Thus, every scenario was run 50 times in order to estimate the mean values and standard deviation of the output parameters. As output parameters we calculated the total number of individuals $(N)$, total basal area in $\mathrm{m}^{2}$ :

$$
\mathrm{BA}=\sum_{i=1}^{N}\left[\frac{\pi\left(\mathrm{dbh}_{i}\right)^{2}}{4}\right]
$$

mean number of alleles over all loci:

$$
A=\sum_{i=1}^{l} k_{i}
$$

where $k$ is the number of alleles in locus $i$, mean expected heterozygosity:

$H_{\mathrm{e}}=\frac{1}{l} \sum_{i=1}^{l}\left(1-\sum p_{k}^{2}\right)$

where $p_{k}$ is the frequency of the $k$ allele in the locus $i$ and $l$ is the number of loci, effective number of alleles:

$$
A_{\mathrm{e}}=\frac{1}{l} \sum_{i=1}^{l}\left[\frac{1}{\left(1-H_{\mathrm{e}(i)}\right)}\right]
$$


where $H_{\mathrm{e}(i)}$ is the expected heterozygosity in the locus $i$, mean observed heterozygosity:

$H_{\mathrm{o}}=\frac{1}{l} \sum_{i=1}^{l}\left(1-P_{i i}\right)$,

where $P_{i i}$ is the frequency of homozygous genotypes in the locus $l$, mean fixation index:

$F=\frac{1}{l} \sum_{i=1}^{l}\left[1-\left(\frac{H_{\mathrm{o}(i)}}{H_{\mathrm{e}(i)}}\right)\right]$,

where $H_{\mathrm{o}(i)}$ is the observed heterozygosity in the locus $i$. Gregorius genetic distance between the initial population (year 1) and the population at the end of the simulations:

$D_{\text {Gregorius }}=\frac{1}{l} \sum_{j=1}^{l}\left[0.5 \sum_{i=1}^{n}\left|p_{i j}(X)-p_{i j}(Y)\right|\right]$,

where $p_{i}$ is the frequency of the allele $i$ at locus $j$, in the population at time $X$ (year 1) and time $Y$ (last year of simulation); $n$ the number of alleles; $l$ the number of loci; and NG is the number of single-locus genotypes at all loci. We used the genetic distance of Gregorius instead of $F_{\mathrm{ST}}$ statistics to quantify the difference between initial and final genetic composition of the populations because $F_{\mathrm{ST}}$ has been proven to be a weak measure of genetic differences especially for highly variable microsatellites (Gregorius et al., 2007; Hedrick, 2005).

\section{Results}

\subsection{Demographic parameters}

The control populations (without logging) maintained a stable population size relative to the initial population throughout the simulation period (Tables 2 and 3). Equilibrium population sizes (including juveniles) were roughly similar (about 500 individuals) for Bagassa, Hymenaea, and Symphonia, but Manilkara maintained larger control population sizes. However, of the four study species, only Symphonia was able to recover its population size under a cutting cycle of 65 years for both 45 - and 60 -cm cutting diameters (Table 3 ). In addition, in one case, Manilkara recovered numbers (under 65/60). For Bagassa, Hymenaea, and Manilkara, short cutting cycles resulted in smaller post-logging population sizes. For each of the two cutting diameters, the shorter cycle yielded smaller populations (larger proportional decrease in $N$ ) after six cumulative logging cycles. Within each of the two different cutting cycles, however, a larger cutting diameter permitted the logged population to recover more of its initial population size.

Bagassa showed the largest reduction in population sizes under all the cutting regimes (Table 3 ). With a short cycle and small cutting diameter (30/45), its final population after six cuts was only $47 \%$ of the initial population size. Manilkara was intermediate in its population size decrement after logging (except under the lightest logging pressure), but, like Bagassa, was more strongly affected by shorter cutting cycles. For Hymenaea there was no difference in population recovery

Table 3

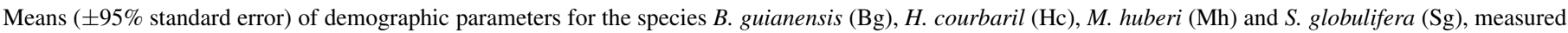

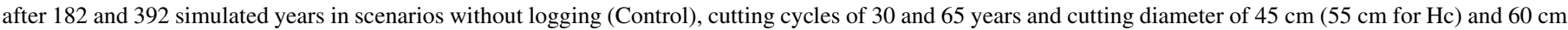

\begin{tabular}{|c|c|c|c|c|}
\hline Scenarios & $N$ & $N \%$ change & BA & BA $\%$ change \\
\hline Bg_182_Control & $478 \pm 2.8$ & & $0.054 \pm 0.001$ & \\
\hline Bg_182_30_45 & $224 \pm 1.9$ & -53.1 & $0.005 \pm 0.000$ & -90.7 \\
\hline Bg_182_30_60 & $262 \pm 2.5$ & -45.2 & $0.011 \pm 0.000$ & -79.6 \\
\hline Bg_392_Control & $439 \pm 3.3$ & & $0.054 \pm 0.001$ & \\
\hline Bg_392_65_45 & $311 \pm 2.5$ & -29.2 & $0.024 \pm 0.001$ & -55.6 \\
\hline Bg_392_65_60 & $345 \pm 2.8$ & -21.4 & $0.038 \pm 0.001$ & -29.6 \\
\hline Hc_182_Control & $538 \pm 3.3$ & & $0.132 \pm 0.002$ & \\
\hline Hc_182_30_55 & $466 \pm 1.7$ & -13.4 & $0.042 \pm 0.001$ & -68.2 \\
\hline Hc_182_30_60 & $482 \pm 1.7$ & -10.4 & $0.049 \pm 0.001$ & -62.9 \\
\hline Hc_392_Control & $555 \pm 3.0$ & & $0.132 \pm 0.002$ & \\
\hline Hc_392_65_55 & $478 \pm 2.5$ & -13.9 & $0.050 \pm 0.001$ & -62.1 \\
\hline Hc_392_65_60 & $494 \pm 1.7$ & -11.0 & $0.057 \pm 0.001$ & -56.8 \\
\hline Mh_182_Control & $992 \pm 1.5$ & & $0.750 \pm 0.002$ & \\
\hline Mh_182_30_45 & $689 \pm 1.5$ & -30.6 & $0.185 \pm 0.001$ & -75.3 \\
\hline Mh_182_30_60 & $794 \pm 1.5$ & -19.9 & $0.307 \pm 0.002$ & -59.1 \\
\hline Mh_392_Control & $918 \pm 1.5$ & & $0.751 \pm 0.003$ & \\
\hline Mh_392_65_45 & $818 \pm 1.6$ & -10.9 & $0.355 \pm 0.002$ & -52.7 \\
\hline Mh_392_65_60 & $956 \pm 1.6$ & +4.6 & $0.491 \pm 0.003$ & -34.7 \\
\hline SG_182_Control & $569 \pm 5.8$ & & $0.035 \pm 0.001$ & \\
\hline SG_182_30_45 & $576 \pm 3.3$ & +1.2 & $0.025 \pm 0.000$ & -28.6 \\
\hline SG_182_30_60 & $555 \pm 4.2$ & -2.5 & $0.028 \pm 0.000$ & -20.0 \\
\hline SG_392_Control & $551 \pm 6.9$ & & $0.034 \pm 0.001$ & \\
\hline SG_392_65_45 & $646 \pm 5.5$ & +14.7 & $0.034 \pm 0.000$ & 0.0 \\
\hline SG_392_65_60 & $623 \pm 5.0$ & +11.6 & $0.034 \pm 0.000$ & 0.0 \\
\hline
\end{tabular}

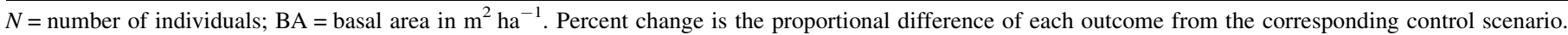


between 30 - and 65-year cycles. There was an effect of cutting cycle on population size, but because the cutting diameter between the treatments $(55 \mathrm{~cm}$ vs. $60 \mathrm{~cm}$ ) differed only slightly, differential effects of cutting diameter were small. Population size in Symphonia, however was virtually unaffected by the logging scenarios. Although its final population size was reduced, on average, $2.5 \%$ with a cycle of 30 years and a cutting diameter of $60 \mathrm{~cm}$, this is virtually undistinguishable from results in the corresponding control runs. Thus, only Symphonia showed consistent numerical recovery from logging scenarios.

As was true for population sizes, the control simulations were effective in maintaining initial basal areas over the period of our models (upper, dotted lines, Fig. 2). Thus, logging effects on demographic variables measured against control values are essentially the same as effects measured against starting conditions. However, equilibrium basal areas varied widely, with Symphonia and Bagassa maintaining much smaller standing basal areas than the other two species. In almost every case, logging had a much stronger impact on basal area than on population size (Table 3); proportional reductions in basal area were close to double that of population size. Only Symphonia was able to recover its starting basal area after logging, and only under a long (65-year) cutting cycle.

(A)
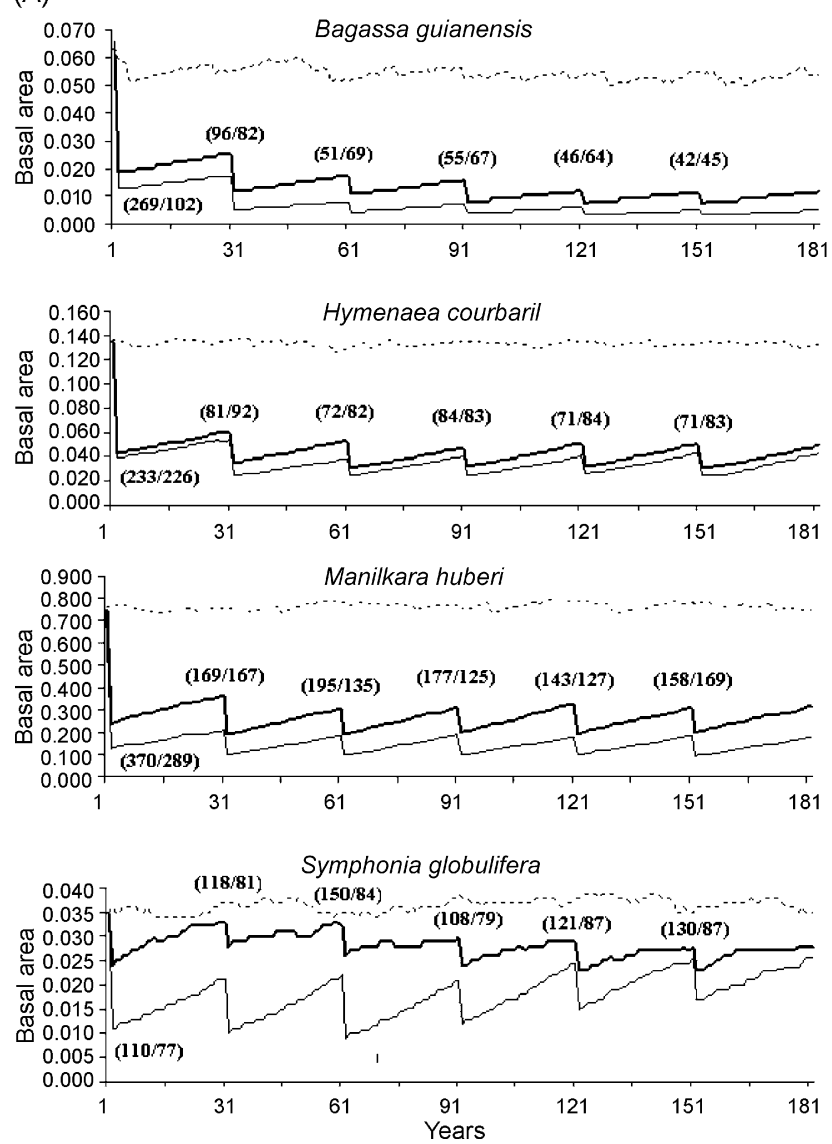

As with population size, Bagassa showed the largest proportional effects on basal area under strong, long-term logging pressure. With logging parameters currently in use in Brazil (30 years, $45 \mathrm{~cm} \mathrm{dbh),} \mathrm{the} \mathrm{basal} \mathrm{area} \mathrm{of} \mathrm{Bagassa}$ after six cutting cycles was reduced to only $9 \%$ of its starting size. Hymenaea lost almost $70 \%$ of its basal area under strong logging pressure, and 57\% under the most liberal of logging scenarios. Manilkara was also strongly affected by short cycles and lower cutting diameters, recovering only $65 \%$ of its basal area under the most relaxed cutting regimes. Even Symphonia showed a loss of 20-30\% of its basal area after logging under short (30-year) cutting cycles, although under 65 -year cutting scenarios it was able to recover its standing basal area.

Fig. 2 shows the comparative effects of cutting cycle and cutting diameter on basal area in all four species. In this figure, only Symphonia achieves nominal sustainability in our scenarios, and only with cutting cycles almost double that currently in use in the Amazon. No other scenarios predict basal area recovery between logging episodes, even under the longest cutting intervals and largest cutting diameters. For Hymenaea, the small difference in cutting diameters $(55 \mathrm{~cm}$ vs. $60 \mathrm{~cm})$ clearly has a minimal effect on basal area recovery. Longer

(B)
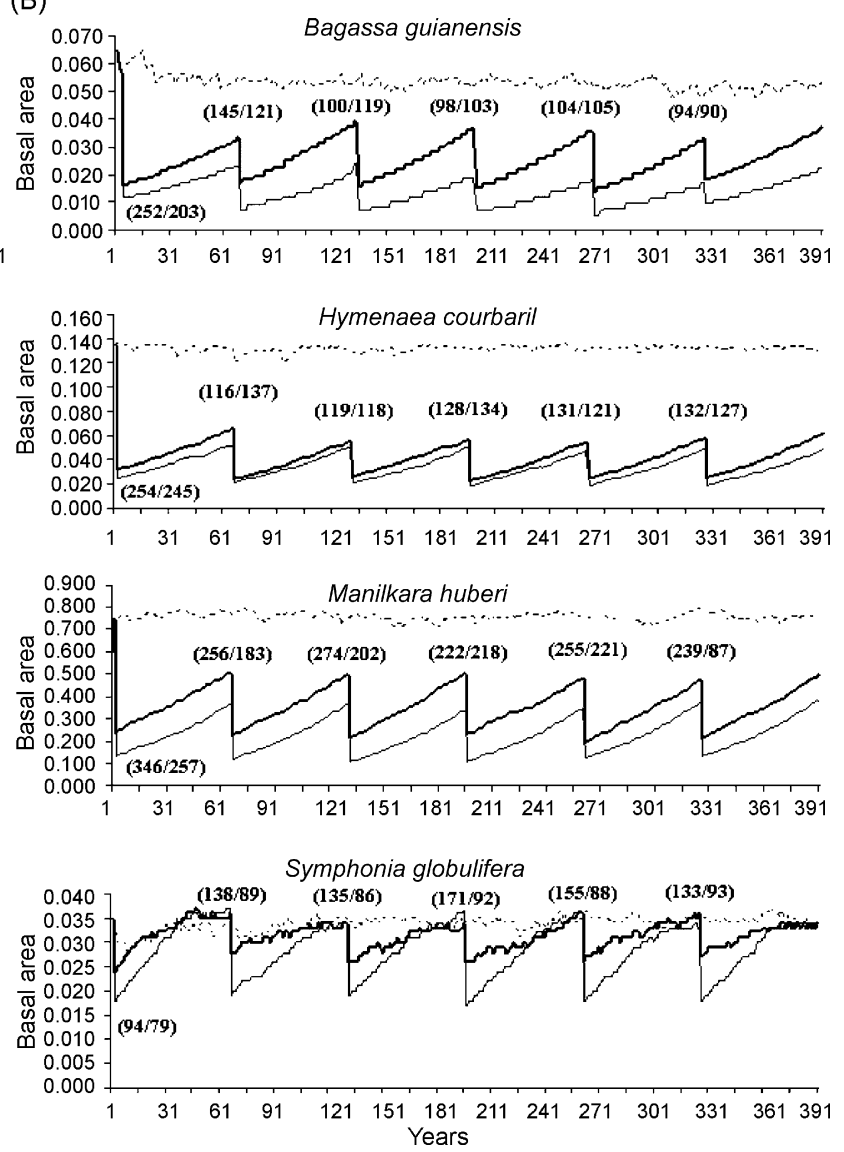

Fig. 2. Changes in basal area $\left(\mathrm{m}^{2} \mathrm{ha}^{-1}\right)$ under the controls and various logging scenarios. Panel (A) shows basal area under a 30-year cutting cycle; panel (B) shows 65-year cycles. Separate graphs are shown for each species: Bagassa guianensis, Hymenaea courbaril, Manilkara huberi and Symphonia globulifera. The upper, dotted line shows the control scenario; bold line represents a $60-\mathrm{cm}$ cutting diameter, and fine line is a $45-\mathrm{cm}$ cutting diameter (55 $\mathrm{cm}$ for Hymenaea). Note large differences in the scale on the $y$-axis. Graphs represent results for a single, randomly chosen simulation for each species. The first number in parentheses represents the number of logged trees with a minimum cutting dbh of $45 \mathrm{~cm}$ and the second, the number under a minimum cutting dbh of $60 \mathrm{~cm}$ in each cutting event. 
cutting cycles permit the population to recover slightly more basal area between logging events, but the potential harvest is permanently reduced to only $30 \%$ of its initial volume. Manilkara shows a similar permanent reduction in basal area, although the effects of cutting diameter are more pronounced for this species. Although it shows complete recovery in numbers of individuals under a relatively light, $65-$ year $/ 60-\mathrm{cm}$ logging cycle (Table 3 ), those individuals comprise only $65 \%$ of the initial basal area. From the perspective of basal area, Manilkara clearly is unsustainable under even this lightlogging regime.

Of the four species, Bagassa shows the biggest difference in the impact of logging cycle on basal area regrowth. Under short cutting cycles, Bagassa continues to lose basal area with each additional cutting regime. However, with 65-year cutting cycles, its basal area rebounds to slightly higher, although still unsustainable, levels between cuts.

\subsection{Genetic variables}

Basic population genetics theory demonstrates the important effects of population size (and therefore, genetic drift) on measures of genetic variability. Thus, we examined the Pearson correlation coefficient between final population size $(N)$ and genetic variables $\left(A, A_{\mathrm{e}}, H_{\mathrm{o}}, G_{\mathrm{D}}\right.$, and $\left.\mathrm{NG}\right)$ using Proc CORR (SAS Institute, 1999). Population size is significantly correlated with all the genetic variables except genetic distance (Table 4). However, final population sizes in the logging scenarios
Table 4

Estimates of the Pearson correlation between population size $(N)$ and various genetic parameters

\begin{tabular}{lll}
\hline Parameter & $\hat{r}$ & Probability \\
\hline Number of alleles, $A$ & 0.44 & 0.030 \\
Effective number of alleles, $A_{\mathrm{e}}$ & 0.51 & 0.010 \\
Observed heterozygosity, $H_{\mathrm{o}}$ & 0.63 & 0.001 \\
Gregorius genetic distance, $D_{\text {Gregorius }}$ & 0.11 & 0.622 \\
Number of single-locus genotypes, NG & 0.51 & 0.012 \\
\hline
\end{tabular}

differed widely as a result of ecological differences among the four study species, and so our models can provide useful generalizations about the predicted effects of long-term logging processes on genetic parameters.

Even in the control scenarios, all four species experienced a loss of alleles $(A)$ and a decline in the number of effective alleles per locus $\left(A_{\mathrm{e}}\right)$ relative to the starting populations (Table 5). These losses are larger for the 392-year simulations than for the corresponding 182-year runs, implying that genetic drift, even in these relatively large populations, was eliminating alleles from the population over these time frames. As with the demographic variables, Symphonia showed only small losses in total allelic richness under short cutting cycles, and no such losses (and, in fact, a slight gain, relative to the control) with longer cutting intervals. However, for the other three species, logging scenarios resulted in some loss of alleles. In general, the most stringent logging parameters (30 years, $45 / 55 \mathrm{~cm} \mathrm{dbh}$ ) produced the largest allelic losses over the control scenarios; for

Table 5

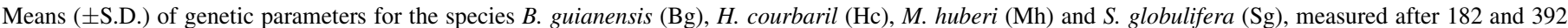
simulated years in scenarios without logging (Control), cutting cycles of 30 and 65 years and cutting diameter of $45 \mathrm{~cm}$ and $60 \mathrm{~cm}$

\begin{tabular}{|c|c|c|c|c|c|c|c|c|}
\hline Scenarios & $A$ & $A_{\mathrm{e}}$ & $H_{\mathrm{o}}$ & $F$ & $D_{\text {Gregorius }}$ & $D_{\mathrm{G}} \%$ change & NG & NG $\%$ change \\
\hline Bg_182_Control & $31.9 \pm 0.00$ & $2.47 \pm 0.00$ & $0.618 \pm 0.000$ & $-0.039 \pm 0.001$ & $0.025 \pm 0.000$ & & $84.5 \pm 0.1$ & \\
\hline Bg_182_30_45 & $30.0 \pm 0.03$ & $2.44 \pm 0.00$ & $0.599 \pm 0.001$ & $-0.018 \pm 0.001$ & $0.083 \pm 0.001$ & +232.0 & $66.6 \pm 0.2$ & -21.2 \\
\hline Bg_182_30_60 & $30.7 \pm 0.03$ & $2.46 \pm 0.00$ & $0.607 \pm 0.001$ & $-0.021 \pm 0.001$ & $0.052 \pm 0.001$ & +108.0 & $72.7 \pm 0.2$ & -14.0 \\
\hline Bg_392_Control & $31.6 \pm 0.03$ & $2.46 \pm 0.00$ & $0.597 \pm 0.000$ & $-0.007 \pm 0.001$ & $0.037 \pm 0.000$ & & $82.3 \pm 0.1$ & \\
\hline Bg_392_65_45 & $29.0 \pm 0.05$ & $2.41 \pm 0.00$ & $0.584 \pm 0.001$ & $0.001 \pm 0.001$ & $0.081 \pm 0.001$ & +118.9 & $69.7 \pm 0.2$ & -15.3 \\
\hline Bg_392_65_60 & $30.1 \pm 0.05$ & $2.45 \pm 0.00$ & $0.588 \pm 0.001$ & $0.005 \pm 0.001$ & $0.062 \pm 0.001$ & +67.6 & $74.6 \pm 0.2$ & -9.4 \\
\hline Hc_182_Control & $170.5 \pm 0.69$ & $3.59 \pm 0.02$ & $0.618 \pm 0.002$ & $0.146 \pm 0.003$ & $0.063 \pm 0.002$ & & $846.3 \pm 8.4$ & \\
\hline Hc_182_30_55 & $147.6 \pm 1.41$ & $3.54 \pm 0.04$ & $0.622 \pm 0.004$ & $0.139 \pm 0.005$ & $0.101 \pm 0.002$ & +60.3 & $752.2 \pm 7.6$ & -11.1 \\
\hline Hc_182_30_60 & $149.9 \pm 1.11$ & $3.55 \pm 0.04$ & $0.620 \pm 0.004$ & $0.140 \pm 0.004$ & $0.091 \pm 0.002$ & +44.4 & $772.3 \pm 5.8$ & -8.7 \\
\hline Hc_392_Control & $164.3 \pm 0.83$ & $3.57 \pm 0.02$ & $0.630 \pm 0.002$ & $0.126 \pm 0.003$ & $0.083 \pm 0.002$ & & $819.7 \pm 6.2$ & \\
\hline Hc_392_65_55 & $148.9 \pm 1.19$ & $3.46 \pm 0.04$ & $0.627 \pm 0.003$ & $0.117 \pm 0.004$ & $0.135 \pm 0.003$ & +62.7 & $689.6 \pm 10.2$ & -15.9 \\
\hline Hc_392_65_60 & $153.3 \pm 1.03$ & $3.47 \pm 0.04$ & $0.626 \pm 0.004$ & $0.121 \pm 0.004$ & $0.117 \pm 0.003$ & +41.0 & $720.9 \pm 8.5$ & -12.1 \\
\hline Mh_182_Control & $119.7 \pm 0.2$ & $6.38 \pm 0.02$ & $0.729 \pm 0.001$ & $0.136 \pm 0.001$ & $0.053 \pm 0.001$ & & $669.4 \pm 1.5$ & \\
\hline Mh_182_30_45 & $114.0 \pm 0.2$ & $6.24 \pm 0.03$ & $0.734 \pm 0.001$ & $0.125 \pm 0.002$ & $0.088 \pm 0.001$ & +66.0 & $581.0 \pm 1.7$ & -13.2 \\
\hline Mh_182_30_60 & $116.3 \pm 0.3$ & $6.34 \pm 0.02$ & $0.735 \pm 0.002$ & $0.127 \pm 0.002$ & $0.070 \pm 0.001$ & +32.1 & $616.5 \pm 2.0$ & -7.9 \\
\hline Mh_392_Control & $116.8 \pm 0.2$ & $6.33 \pm 0.03$ & $0.726 \pm 0.001$ & $0.137 \pm 0.002$ & $0.073 \pm 0.001$ & & $639.6 \pm 2.1$ & \\
\hline Mh_392_65_45 & $109.0 \pm 0.3$ & $6.15 \pm 0.03$ & $0.727 \pm 0.001$ & $0.132 \pm 0.002$ & $0.120 \pm 0.001$ & +64.4 & $570.8 \pm 3.0$ & -10.8 \\
\hline Mh_392_65_60 & $112.6 \pm 0.2$ & $6.28 \pm 0.03$ & $0.731 \pm 0.001$ & $0.130 \pm 0.002$ & $0.091 \pm 0.001$ & +24.7 & $619.3 \pm 2.5$ & -3.2 \\
\hline SG_182_Control & $138.3 \pm 0.44$ & $9.68 \pm 0.09$ & $0.792 \pm 0.003$ & $0.116 \pm 0.004$ & $0.078 \pm 0.002$ & & $859.6 \pm 7.3$ & \\
\hline SG_182_30_45 & $136.7 \pm 0.50$ & $9.45 \pm 0.10$ & $0.787 \pm 0.002$ & $0.120 \pm 0.003$ & $0.088 \pm 0.002$ & +12.8 & $841.9 \pm 5.9$ & -2.1 \\
\hline SG_182_30_60 & $136.7 \pm 0.53$ & $9.51 \pm 0.09$ & $0.789 \pm 0.003$ & $0.118 \pm 0.003$ & $0.085 \pm 0.002$ & +9.0 & $836.8 \pm 5.3$ & -2.7 \\
\hline SG_392_Control & $132.1 \pm 0.64$ & $9.39 \pm 0.12$ & $0.780 \pm 0.003$ & $0.126 \pm 0.003$ & $0.116 \pm 0.002$ & & $803.2 \pm 8.1$ & \\
\hline SG_392_65_45 & $133.3 \pm 0.64$ & $9.44 \pm 0.12$ & $0.780 \pm 0.004$ & $0.127 \pm 0.004$ & $0.112 \pm 0.002$ & -3.4 & $855.6 \pm 7.7$ & +6.1 \\
\hline SG_392_65_60 & $133.5 \pm 0.58$ & $9.39 \pm 0.11$ & $0.779 \pm 0.003$ & $0.128 \pm 0.003$ & $0.110 \pm 0.002$ & -5.2 & $844.7 \pm 7.2$ & +4.9 \\
\hline
\end{tabular}

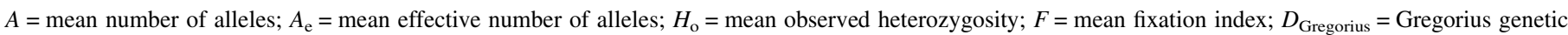

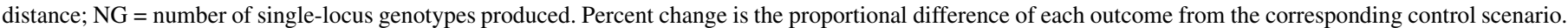


Hymenaea, this was $13.4 \%$, and for Manilkara, $4.8 \%$. Bagassa, however, lost the most alleles (8.2\%) under a logging scenario with a 65-year cycle and a $45-\mathrm{cm}$ cutting diameter. Effective numbers of alleles per locus showed generally similar patterns.

Values of $H_{\mathrm{o}}$ and $F$ showed only very small changes as a result of logging scenarios, and the patterns of change for each of the species generally followed results for other variables (Table 5). In Hymenaea and Manilkara, fixation indices declined slightly in the logging scenarios. Symphonia showed no consistent changes in fixation in the logging models, and in Bagassa, the slight heterozygote excess of the control scenarios became marginally less pronounced after six cycles of logging.

Gregorius genetic distance $\left(G_{\mathrm{D}}\right)$ was the variable which differed most between control and logging scenarios (Table 5). For all four species, the effect was strongest under a short cycle and a small cutting diameter. Relative to corresponding control scenarios, almost all logging scenarios showed sizeable increases in Gregorius genetic distance at the end of the simulation periods. The exception was, again, in Symphonia. With a short (30-year) cutting cycle, genetic distance after logging in Symphonia was, in fact, very slightly higher than in the control (probably simply a result of stochastic elements in the modelling process). However, with a longer cutting interval, the logged population actually diverged less from the starting population than did the control scenarios. Genetic distance in Symphonia is thus little impacted by logging in our simulations, especially under long cutting cycles.

For Bagassa, the effects of shorter cutting cycle were stronger than the effects of lower cutting diameter in increasing genetic divergence in logged populations. However, within each of the two-modelled cutting cycles, logging of smaller trees accentuated the genetic divergence of the logged population from its starting point. In Bagassa, the strongest logging treatment caused a $232 \%$ increase in genetic distance in the final population from analogous measures in the control population. Overall effects were also sizable for Manilkara and Hymenaea. But genetic distances in these two species were most affected by minimum cutting diameter, and not by length of the cutting cycle. Increases in genetic distance after logging were almost identical between the two contrasting cutting diameters, regardless of the cutting cycle.

The number of single-locus genotypes being produced in a population is a function of the number of loci analyzed, the allelic diversity at these loci, and the mating system by which gametes are brought together. Thus, we cannot directly compare changes in genotypes among species. However, Table 5 shows that proportional reductions in numbers of genotypes between species follow patterns similar to those of other genetic parameters. Loss in the number of single-locus genotypes was greatest in Bagassa, which had the lowest level of genetic diversity and the smallest post-logging population size. Genotypic diversity in Symphonia was little affected by logging. In the other two species, genetic variability was more strongly affected by short cutting cycles. Under 65-year cycles, Manilkara maintained $90 \%$ or more of its genotypic diversity. Hymenaea showed similar proportional changes in numbers of genotypes, regardless of logging patterns. The 5 -cm difference in minimum cutting diameter in Hymenaea produced a reduction in numbers of genotypes roughly equal to the reductions also caused by longer cutting cycles (and thus, also, a longer time-course over which drift could operate).

\section{Discussion}

\subsection{Realism of the model}

A central goal of this simulation study was to explore how species with different ecological and life-history traits might be affected by logging. To that end, we created initial populations that conformed to field data in both demographic and genetic respects. Size class distributions, juvenile and adult densities, fixation indices, allele frequencies, and spatial genetic structures for each starting population were equivalent to those observed in our real populations (Table 2). In addition, we used field data to parameterize the yearly processes of growth, mating, seed production, and recruitment based on measurements from real populations (Table 1). Growth rates and diameter distribution categories were species-specific, as were phenological patterns, pollinator movements, and seed dispersal properties. Thus, we have used the best available data to construct realistic scenarios that encapsulate critical ecological differences between these four species. Control populations were demographically stable over the 182- and 392-year simulations, maintaining both initial population sizes and starting basal areas. This indicates that the ecological parameters used for running the model were not only realistic, but were appropriate to generate the age and size structure of the four species populations actually measured in the Tapajós National Forest.

\subsection{Population size and basal area}

Logged populations decreased in size and in basal area after each logging episode and, growing according to speciesspecific growth rates, were highly variable in their ability to regain population size between logging episodes. Among the study species, Symphonia had the lowest standing basal area, as well as the smallest total basal area removed, even in the first cut. It was also the least affected, demographically, by logging. Under different combinations of cutting cycles and cutting diameters, Symphonia was able, or nearly able, to recoup its pre-logging population size and basal area. This can be explained by its relatively high densities in juvenile size classes, its fast growth rate (Table 1) and its low stand basal area in unlogged forest. After each cut, the population of Symphonia consisted of many smaller trees which showed rapid ingrowth into larger diameter classes. Its small size $(20 \mathrm{~cm})$ at reproductive maturity ensured that, even after logging, many reproductive individuals remained. A large fraction of these reproductive individuals reproduced annually, so seedling establishment and sapling growth kept the population large, even after logging. In addition, the maximum diameter (95th percentile) for survivorship in Symphonia was only $80 \mathrm{~cm}$, producing rapid population turnover. In the most relaxed 
logging scenarios, with 65 years between harvests, even trees below a 45-cm cutting limit could grow almost to their maximum size before the next harvest event. As a result, Symphonia was demographically much more resilient than the other three species. While it did not recover its basal area in the short (30-year) logging cycles, a 65-year cutting interval could, all other things being equal, permit harvesting of Symphonia basal area at a sustainable level.

In contrast, the other three species all showed dramatic and negative post-logging population dynamics (Fig. 2). While there were important differences in their responses to logging, none of these species - all of them important timber trees in Amazonia - could recover even 1/3 of their initial basal areas under current Brazilian logging practices, even after a single cut. All three of these species are large, canopy members of uncut forests, reaching diameters of up to $150 \mathrm{~cm}$ at maturity. Thus, their standing basal area, before logging, is mostly housed in a few, very large individuals. Even under relatively rapid growth, a logged population will not be able to recover the largest diameter classes by ingrowth between logging intervals, even under a long cutting cycle. Despite these similarities, the species do, however, behave differently in our simulations. Thus, it appears that a complex of ecological and demographic variables affect how species will respond to harvest pressures.

\subsection{Genetic variables}

All four of our species showed a slight reduction in the number of alleles $(A)$ and the number of effective alleles $\left(A_{\mathrm{e}}\right)$ under most logging scenarios, and a corresponding loss in the number of single-locus genotypes (Table 5), a variable highly correlated $(P<0.0001)$ with allelic diversity. Reduction in the population size after a logging episode creates a bottleneck effect in trees above the cutting diameter (individuals most likely to be reproductive). However, the loss of alleles will depend on the magnitude of the bottleneck, the time over which it persists, and the frequency of alleles at a locus (Nei, 1975). Rare alleles will be the first to be lost. Loss of alleles after logging has been documented in several studies comparing managed and natural populations (Rajora et al., 2000; Degen et al., 2002, 2006; Glaubitz et al., 2003; Lowe et al., 2005).

Despite the fact that population sizes in our study species declined after each logging episode, a large population of smaller trees always remained. Except for a single year of higher post-logging mortality, juveniles in our model continued to grow into larger diameter classes and then to reproduce at size-specific rates equivalent to those before logging. Thus, under the conditions of our scenario, there was never a severe bottleneck, and few alleles were lost, even after six logging cycles. Although allele frequencies may change between generations (Frankel and Soulé, 1981; Ericksson, 1996), populations of more than 100 individuals are unlikely to lose common alleles (Krusche and Geburek, 1991). It is these common alleles which are generally expected to be adaptively important for the fitness of the population (Gregorius, 1991). Although the SSR loci we used are expected to be neutral gene markers, the same processes which result in their loss will also affect coding portions of the genome. And the loss of even rare alleles should not be discounted as unimportant. It is these rare alleles, not favored by current conditions, which are thought to provide genetic variation that permits a population to adapt to future environmental or biotic conditions, such as parasites, predators, or changes in climate (Krusche and Geburek, 1991; Mosseler et al., 2003; Rajora and Pluhar, 2003; Hawley et al., 2005).

That heterozygosity and allelic diversity did not show large declines in our simulations suggests that these genetic parameters are less sensitive to potential negative impacts of forest logging. In their review of 31 studies on the genetic impacts of degradation and fragmentation on tropical forests, Lowe et al. (2005) also noted that, over all, measurements of genetic diversity were less sensitive to the consequences of disturbance than measures of reproductive output or fitness. A similar pattern of sensitive and less sensitive genetic parameters was observed by Degen et al. (2006) in their Eco-Gene simulation studies of the effects of forest logging on genetic diversity of the tropical tree species Sexonia rubra, Symphonia globulifera, Vouacapoua americana and Dicorynia guianensis in French Guiana. Buchert et al. (1997) compared pre-harvest and post-harvest gene pools of two adjacent old-growth stands of Pinus strobus in central Ontario (Canada) using allozymes. They detected a reduction of $25 \%$ in the number of alleles after logging. This included the loss of about $40 \%$ of alleles with low frequencies $(0.25<p \geq 0.01)$ and $80 \%$ of rare alleles $(p<0.01)$. In our logging scenarios, the effective number of alleles per locus and the heterozygosity were only little affected, indicating that it was rare alleles being lost. Heterozygosity is depleted by drift very slowly, at the rate of $1 / 2 N_{\mathrm{e}}$ per generation (Savolainen and Kärkkäinen, 1992). Thus population genetic theory concurs that these output parameters should not be affected except by very severe reductions in population size, beyond the levels typically found in a logging operation.

Empirical studies like those cited above measure the immediate effects of selective logging on a population, and thus document short-term impacts of logging on genetic diversity. In addition, however, they often evaluate $H_{\mathrm{o}}$ based on adults in the post-logged sites, ignoring the potential genetic contributions which may eventually come from the juveniles in the logged site. In contrast, our simulations measured cumulative, long-term genetic changes after six logging cycles. Thus, our logging scenarios included repeated, cyclic losses of large individuals, with gradual regrowth from the unlogged population. Assuming that logging is random in its removal of adult genotypes and that the advance regeneration reflects the genetic makeup of the larger trees, then juveniles serve as a reservoir of allelic diversity. Thus, our measures of gene diversity and allele richness are more conservative than those of at least some empirical studies, because they include the genetic memory that is housed in the large population of young trees in the post-logged forest.

Fixation index $(F)$ also changed relatively little, in our scenarios, even under strong logging pressure. The fixation 
index is generally considered a measure of inbreeding, but is better thought of, in this case, as a measure of heterozygote deficiency. Although the initial population of Bagassa had no strong spatial genetic structure, the other three species did show evidence of such structure. For example, in Symphonia the average coancestry coefficient for the distance class from 0 to $50 \mathrm{~m}$ between trees $\left(\hat{\theta}_{x y}=0.119 ; p<0.05\right)$ was about that expected in half-sibs (Carneiro et al., 2007). Thus, with such strong population substructuring, the high fixation indexes detected in Hymenaea, Manilkara, and Symphonia could be due to a Wahlund effect.

Genetic distance $\left(D_{\mathrm{g}}\right)$ and single-locus genotypic diversity (NG) showed larger changes than other genetic variables, in our simulations. Like $A, A_{\mathrm{e}}$, and $H_{\mathrm{o}}$, NG is strongly correlated with population size. As was true for demographic parameters, the largest reductions in NG came in Bagassa, and the smallest, in Symphonia, with Manilkara and Hymenaea intermediate in their responses. Ecological factors which maintain larger population sizes - such as recruitment and juvenile population density - will keep alleles in the population, thus permitting them to be expressed in genotypes. In addition, factors such as density of reproductive individuals and flowering frequency will enhance gene movement among individuals, thus creating larger numbers of genotypic permutations. However, forest logging can affect the mating system of the species by increasing the distance between conspecifics and reducing the density of reproductive individuals in the population (Murawski et al., 1994; Obayashi et al., 2002; Ledig et al., 2005). Thus, the behavior of pollinators and their ability to move long distances will be a determining factor in mating patterns after disturbance. Reduction in the number of adult trees available for mating could also be a factor in reducing numbers of genotypic combinations in the post-logged forest.

Genetic distance shows the most dramatic impacts of logging scenarios in our study. The three large canopy species all showed large increases in the degree to which they diverged from their initial genetic makeup under repeated logging. Since $G_{\mathrm{D}}$ is not correlated to $N$, it cannot be explained simply as a byproduct of demographic differences among the species. Instead, it integrates the joint effects of allelic loss by genetic drift and changes in gene frequencies which arise from non-random mating. It is compounded by pre-existing local genetic structure, changes in that structure over the time of the simulation, variations in individual contributions to the seed arrays, and patterns of gene flow among flowering individuals.

Symphonia showed small increases in genetic distance under short logging cycles, and no effects under long ones. Even a 45$\mathrm{cm}$ cutting diameter removed a relatively small fraction of the population, and the species recovered quickly. Thus, logging of Symphonia produced only a minor impact on genetic distance, relative to the control populations.

Hymenaea and Manilkara showed intermediate levels of change in genetic distance, and in both species, cutting diameter was more important than the length of the cutting cycle in producing these changes (Table 5). A small minimum cutting diameter $(45$ or $55 \mathrm{~cm})$ produced a larger proportional change in genetic distance than a larger cutting size $(60 \mathrm{~cm})$, relative to the controls. Increases in genetic distance for each of the cutting diameters were almost identical, regardless of the cutting cycles in which they were imbedded. This is because proportional changes in $G_{\mathrm{D}}$ were calculated relative to the corresponding controls, all modelled for the appropriate number of years. Since $G_{\mathrm{D}}$ measures the cumulative effects of genetic drift and changes in mating patterns in a population, increasing the cutting cycle simply increased the time period over which both the control and the corresponding logged scenarios changed from their starting genetic makeup. Calculating changes in $G_{\mathrm{D}}$ as proportional deviations from controls essentially normalized the effects of cutting cycle. There was an effect of the logging, but it was due principally to diameter at harvest. At the same time, the magnitudes of these changes were relatively similar between Hymenaea and Manilkara, despite their rather different demographic and reproductive traits.

Bagassa, on the other hand, showed a very different pattern than the other two large, canopy species in how its $G_{\mathrm{D}}$ responded to logging. For this species, both cutting diameter and cutting cycle contributed progressively in increasing the effect of logging on population genetic makeup. While longer cutting cycles produced less dramatic deviations in genetic makeup, their effect was not normalized away by comparison with the controls, as was the case for Hymenaea and Manilkara. And though its juvenile densities were somewhat lower than Hymenaea, overall life-history traits alone would not seem to account for this very different response in genetic makeup. There must be some ecological characteristic of Bagassa which causes it to respond to the length of the cutting cycles, giving short cycles an especially large impact how the genetics of the populations are altered under logging.

The trait which sets Bagassa apart from the other three species is the fact that it, alone, is dioecious. In unlogged, control scenarios, Bagassa should retain the 1:1 sex ratio present in the starting population. But when populations are logged, the few remaining individuals above reproductive size $(42 \mathrm{~cm})$ are very likely to show deviations from a 1:1 ratio, and skewed sex ratios have a strong negative impact on effective population size. Six logging cycles thus have the potential to generate highly unequal male and female frequencies in the reproducing population, especially under short cutting cycles. Thus, unequal genetic contributions to the seed pool progressively accentuate changes in allele frequencies, genetic drift, and genetic distance in Bagassa above those experienced in the other, hermaphroditic species.

\subsection{Limits to the model}

Although the mortality and growth parameters we used produced a steady-state population (essentially constant $N$ and BA) in all eight control scenarios, this does not, in itself, guarantee that the ecological characteristics we used are those that either gave rise to the existing forest, or would be continuously operating in that forest over periods of hundreds of years. The snapshot of forest structure for which we have 
field data is not, in itself, likely to be a steady state. It is much more likely that a complicated history of forest growth combined to produce the Tapajós Forest in 2002. Nonetheless, the ecological parameters we used do reflect the densities and the dynamics of forests currently under logging pressure, and thus represent a reasonable approximation to existing forest dynamics.

We used growth and recruitment parameters which would maintain that forest in perpetuity. However, the actual mortality and recruitment, growth rates and turnover which this forest would experience, in the absence of logging or disturbance, could in fact be more variable than the parameters by which we simulated population persistence in our models, even given the stochasticity inherent in the Eco-Gene program. The SIMFLORA model of van Gardingen et al. (2006) predicted replacement of currently harvested, slow-growing canopy species (such as those in our models) with faster-growing, pioneer species and then fast-growing species of the upper canopy. Like our study, they found that current extraction in the Brazilian Amazon (30-year cycles, with current extracted volumes of $35 \mathrm{~m}^{3} \mathrm{ha}^{-1}$ ) were unsustainable. We used ecological and genetic data to provide a best, data-based picture of the null hypothesis - that of continuous, stable population structure in the current forest exposed to repeated logging pressure. Therefore, our results predict what would happen, if the existing Tapajós forest site were repeatedly cut over 30- or 65-year intervals. If, as van Gardingen et al. (2006) suggest, the species we are modelling will, in fact, disappear from the future forest after logging, the demographic and genetic impacts on these species will be far more pronounced than those we demonstrate. What we can say is that, all other things being equal, logging under our scenarios will produce outcomes for these four species at least as problematic as those suggested in our results.
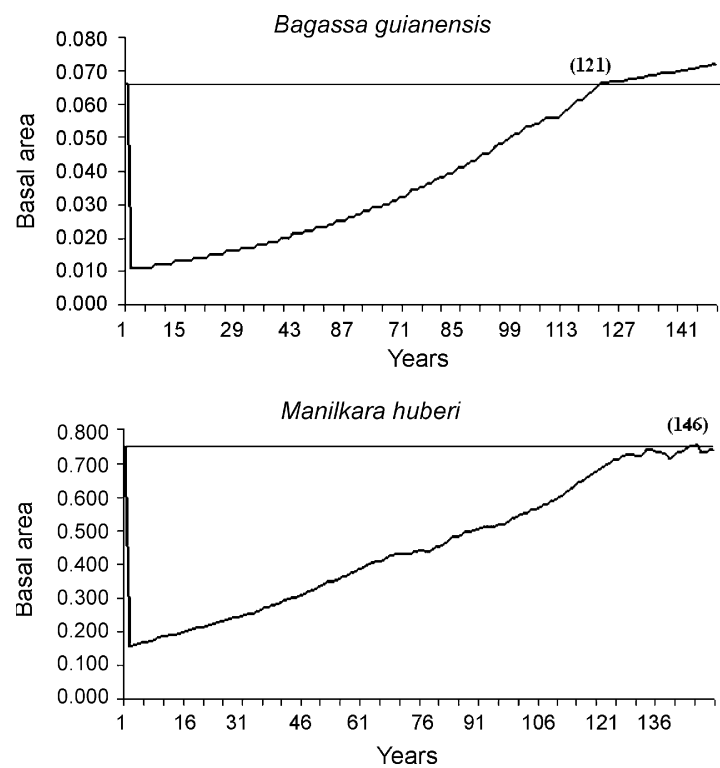

\subsection{Implications for timber harvest in tropical forests}

The results of our study make it clear that planned logging under current, intensive conditions (above $45 \mathrm{~cm} \mathrm{dbh}$, with a 30 -year cycle and up to $90 \%$ of individuals harvested) is unsustainable for all four of the species we modelled. While more relaxed logging parameters resulted in less severe negative effects, even a cutting cycle of 65 years and a minimum size of $60 \mathrm{~cm} \mathrm{dbh}$ could be sustainable only for Symphonia, a species which accounts for only a small extracted basal area in these forests. While our study modelled the longterm effects of six, repeated logging cycles on these populations, the demographic responses of these species did not show cumulative negative impacts with each successive logging. Instead, the regrowth of each species was essentially identical between logging events, as our steady-state ecological parameters would predict. Assuming that there is sufficient recruitment in each inter-logging period, the critical variables for basal area recovery appear to be the rate at which individuals below the cutting diameter grow into larger diameter classes, and also the actual magnitude of standing basal area each species has in the baseline population. This is shown in Fig. 3, which shows the basal area increment of these four species if they are allowed to grow according to our parameters (Table 1) without a second logging event. Symphonia, with the fastest growth rate and the smallest standing basal area, recovers its basal area in 40 years. Bagassa has the slowest growth, but, like Symphonia, a relatively small basal area in the Tapajós forest; it requires 121 years to replace standing basal area. Manilkara and Hymenaea show basal area rebound after 146 and 143 years, respectively.

From a genetic perspective, Bagassa was clearly the species most susceptible to repeated logging. It showed substantial genetic impacts, even under 65-year cutting intervals and with a
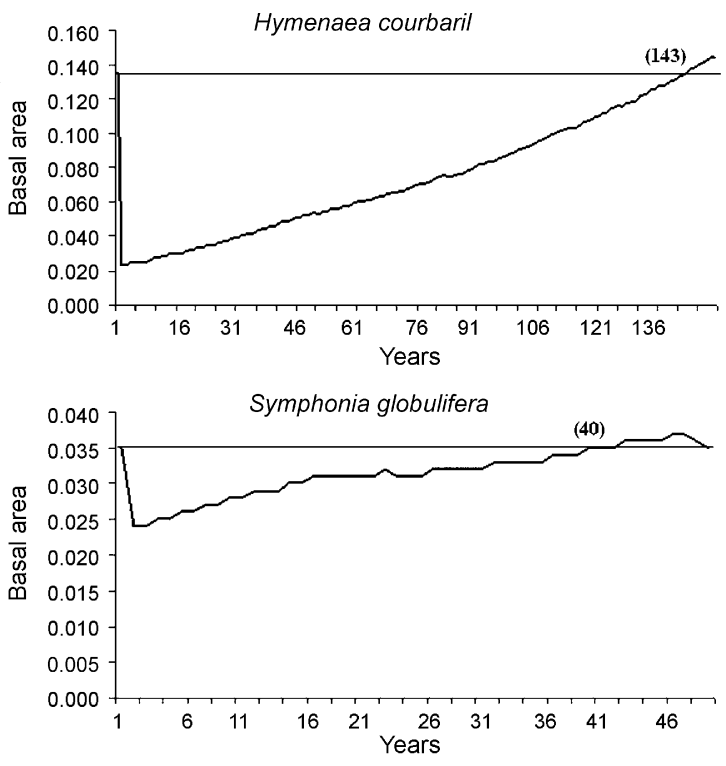

Fig. 3. Basal area $\left(\mathrm{m}^{2} \mathrm{ha}^{-1}\right)$ recovery for the four study species after a single episode of logging, with $90 \%$ of individuals above $45 \mathrm{~cm}$ ( $55 \mathrm{~cm}$ for $\left.H y m e n a e a\right)$ extracted. The horizontal line represents standing basal area in the starting population. Numbers in parentheses show the years for each species to recoup standing basal area. Note the difference scales on the $y$-axis. 
60-cm cutting diameter. Hymenaea and Manilkara showed similar proportional changes in their genetic parameters under the four scenarios, although Manilkara was less affected than Hymenaea under the most relaxed logging parameters. Symphonia showed relatively small shifts in genetic makeup with a 30-year cycle but, as was true for its demography, no negative genetic impacts with a cutting cycle of 65 years. This ranking of species is similar, but not identical to, the relative densities of the species in the Tapajos study plot (Bagassa $<$ Hymenaea $<$ Symphonia $<$ Manilkara). The ranking is, however, exactly the same as the intrinsic levels of genetic diversity found in these four populations (Bagas$s a<$ Hymenaea $<$ Manilkara $<$ Symphonia). The question arises, then, whether changes in genetic makeup are simply a byproduct of differing levels of genetic variation within tropical tree populations. Does low genetic variation predispose a species to more severe genetic consequences under logging? Or are there more complicated factors contributing to the way species respond after cutting?

In fact, species with high genetic diversity should, we believe, show more dramatic shifts after logging. Loci with multiple alleles should also contain a larger proportion of rare alleles, which are most readily lost when population sizes drop. Thus, we do not think that underlying low genetic diversity would, in itself, predispose a species to strong effects of logging. At the same time, the inherent ecological processes which might produce low levels of genetic diversity within a species might also make it susceptible to logging. Populations of species which are at low density, which recruit mostly in infrequent large gaps, and which flower only at large size may, as a result, show lower levels of variation than smaller, faster-growing species. Thus, ecological traits which seem to make species more vulnerable to logging may also drive their inherent levels of genetic variation.

Using a forest growth model, van Gardingen et al. (2006) concluded that logging practices currently used in the Brazilian Amazon (30-year cycles, 45-cm cutting diameters, and $90 \%$ of individuals removed) are unsustainable. They recommended strong reductions in logging intensity, linked to changes in cutting cycles. A study by Schulze et al. (2005) modelling populations of $H$. courbaril, M. huberi and Tabebuia impetiginosa recommended an increase in the cutting cycle (to 60 years) and reductions in logging intensity. Our results corroborate these recommendations. Modifications in cutting cycle, cutting diameter, and harvest intensity represent interacting elements of logging practice which must be adjusted to permit post-logging population recovery. In particular, our study shows the importance of increasing the minimum cutting diameter to $60 \mathrm{~cm} \mathrm{dbh}$ or more, especially for those species which reach reproductive maturity only at very large sizes.

More importantly, our results suggest that we need to fundamentally rethink how logging parameters are applied in the Amazon forest. Each of the four timber species in our models responded differently, both demographically and genetically, to the logging scenarios we used. This suggests that to move beyond simple Reduced Impact Logging (RIL) to actual Sustained Timber Yield (STY) will require harvesting parameters that are species-specific, taking into account the detailed ecological and life-history traits of different timber species. Forest management based on species sustainability is a necessary reflection of the real biological diversity and complexity of the tropical rainforest. From a practical standpoint, this may still involve species groupings, but the categories used should more accurately reflect all the ecological qualities important for species recovery. This approach seems to us to be the next important step in tropical forest management, one which is essential to maintaining, conserving, and effectively using humid tropical forests in the Amazon.

Finally, we need more subtle and complicated simulations which will help us to better understand the long-term effects of cutting parameters on how particular species respond to logging. New models should incorporate more than one species, simulating the ecological complexity of the post-logged forest, and should focus on larger spatial scales to estimate the impact of forest fragmentation, in addition to logging effects. Many tropical tree species have long distance gene flow by pollen and seeds. Thus, in many cases the impacts of logging on genetic diversity can only be estimated and understood if we address the scale of the meta-population. And, as is always true for modelling, results should be tested and confirmed by field studies to the degree possible, to verify and interpret simulation results and to link them to observed biological processes.

\section{Acknowledgements}

The study was financially supported by grants from DFID UK and EMBRAPA Brazil "Dendrogene Project", by a grant for regional co-operation between French Guiana and Brazil "Formation supérieure et diffusion des résultats de la recherche pour la gestion durable des forêts de Guyane Française et d'Amazonie Brésilienne" as well as by the EU-INCO project "Distribution of genetic diversity in tree species from the Neotropics based on DNA fingerprinting assays: Implications for conservation, sustainable utilization and management", (contract number: ICA4-CT-2001-10101, http://thoth.nbu. ac.uk/geneo). The author AMS would like to thank the Conselho National of Desenvolvimento Científico e Tecnológico $(\mathrm{CNPq})$ for granting him a scholarship for postdoctoral studies at the Institut für Forstgenetik und Forstpflanzenzüchtung, Bundesforschungsanstalt für Forst- und Holzwirtschaft $(\mathrm{BFH})$ in Germany. The authors also are grateful to three referees for their important suggestions and constructive criticism of a previous version of this paper.

\section{References}

Aldrich, P.R., Hamrick, J.L., 1998. Reproductive dominance of pasture trees in a fragmented tropical forest mosaic. Science 281, 103-105.

Asner, G.P., Knapp, D.E., Broadbent, E.N., Oliveira, P.J.C., Keller, M., Silva, J.N., 2005. Selective logging in the Brazilian Amazon. Science 130, 480-482. Azevedo, V.C.R., Vison, C.C., Ciampi, A.Y., 2005. Twelve microsatellite loci in Manilkara huberi (Ducke) Standl. (Sapotaceae), an Amazonian timber species. Mol. Ecol. Not. 5, 13-15.

Bergmann, F., Gregorius, H.-R., Larsen, J.B., 1990. Levels of genetic variation in European silver fir (Abies alba) - are they related to the species decline? Genetica $82,1-10$. 
Bittrich, V., Amaral, M.C.E., 1996. Pollination biology of Symphonia globulifera (Clusiaceae). Plant Syst. Evol. 200, 101-110.

Buchert, G.P., Rajora, O.P., Hood, J.V., 1997. Effects of harvesting on genetic diversity in old-growth eastern white pine in Ontario, Canada. Conserv. Biol. 11, 747-758.

Carneiro, F., Sebbenn, A.M., Kanashiro, M., Degen, B., 2007. Low inter-annual variation of mating systems and gene flow of Symphonia globulifera in the Brazilian Amazon. Biotropica 39, 628-636.

Degen, B., Gregorius, H.-R., Scholz, F., 1996. ECO-GENE: a model for simulation studies on the spatial and temporal dynamics of genetic structures of tree populations. Silvae Genet. 45, 323-329.

Degen, B., Scholz, F., 1998. Ecological genetics in forest ecosystems under stress as analyzed by the simulation model Eco-gene. Chemosphere 36, 819-824.

Degen, B., Roubik, D., Loveless, M.D., 2002. Impact of selective logging and forest fragmentation on the seed cohorts of an insect-pollinated tree: a simulation study. In: Degen, B., Loveless, M.D., Kremer, A. (Eds.), Modeling and Experimental Research on Genetic Process in Tropical and Temperate Forest. EMBRAPA Amazônia Oriental, Belém, Brazil, pp. 108110.

Degen, B., Bandou, E., Caron, H., 2004. Limited pollen dispersal and biparental inbreeding in Symphonia globulifera in French Guiana. Heredity 93, 585591.

Degen, B., Blanc, L., Caron, H., Maggie, L., Kremer, A., Gourlet-Fleury, S., 2006. Impact of selective logging on genetic composition and demographic structure of four tropical tree species. Biol. Conserv. 131, 386-401.

Ericksson, G., 1996. A policy suggestion for conservation of Noble Hardwoods genetic resources in Sweden. In: Tutock, J., Ericsson, G., Kleinschmit, J., Canger, S. (Eds.), Noble Hardwoods Network. Report of the first meeting, Escherode, Germany, March 24-27, pp. 147-154.

Frankel, O.H., Soulé, M.S., 1981. Conservation and Evolution. Cambridge University Press, Cambridge.

Gill, G.E., Fowler, R.T., Mori, S.A., 1998. Pollination biology of Symphonia globulifera (Clusiaceae) in Central French Guiana. Biotropica 30, 139-144.

Glaubitz, J.C., Murrell, J.C., Moram, G.F., 2003. Effects of native forest regeneration practices on genetic diversity in Eucalyptus consideniana. Theor. Appl. Genet. 107, 422-431.

Gourlet-Fleury, S., Favrichon, V., Petronelli, P., 2004. Consequences of silvicultural treatments on stand dynamics at Paracou. In: Gourlet-Fleury, S., Guehl, J.M., Laroussinie, O. (Eds.), Lessons Drawn from Paracou, a Long-term Experimental Research Site in French Guiana. Elselvier, Paris, pp. 254-280.

Gregorius, H.R., Degen, B., König, A., 2007. Problems in the analysis of genetic differentiation among populations-a case study in Quercus robur. Silvae Genet. 56, 190-199.

Gregorius, H.-R., 1991. Gene conservation and the preservation of adaptability. In: Seitz, A., Loeschcke, V. (Eds.), Species Conservation: A Populationbiological Approach. Birkhauser Verlag, Berlin, pp. 31-47.

Hawley, G.J., Schaberg, P.G., DeHayes, D.H., Brissette, J.C., 2005. Silviculture alters the genetic structure of an eastern hemlock forest in Maine, USA. Can. J. For. Res. 35, 143-150.

Hedrick, P.W., 2005. A standardized genetic differentiation measure. Evolution $59,1633-1638$

Kanashiro, M., Thompson, I.S., Yared, J.A.G., Loveless, M.D., Coventry, P., Martins-da-Silva, R.C.V., Degen, B., Amaral, W.A., 2002. Improving conservation values of managed forests: the Dendrogene Project in the Brazilian Amazon. Unasylva 209, 26-33.

Krusche, D., Geburek, Th., 1991. Conservation of forest gene resources as related to sample size. For. Ecol. Manage. 40, 145-150.

Ledig, F.T., Hodgskiss, P.D., Johnson, D.R., 2005. Genetic diversity, genetic structure, and mating system of Brewer spruce (Pinaceae), a relict of the Arcto-Tertiary forest. Am. J. Bot. 92, 1968-1975.

Lowe, A.J., Boshier, D., Ward, M., Bacles, C.F.E., Navarro, C., 2005. Genetic resource impacts of habitat loss and degradation; reconciling empirical evidence and predicted theory for Neotropical trees. Heredity 95, 255-273.
Marshall, T.C., Slate, J., Kruuk, L.E.B., Pemberton, J.M., 1998. Statistical confidence for likelihood-based paternity inference in natural populations. Mol. Ecol. 7, 639-655.

Maues, M.M., 2001. Importance of the floral biology and pollinators on the sustainability of forest management. Acta Hort. 561, 81-85.

Maues, M.M., 2006. Estratégias reprodutivas de espécies arbóreas e sua importância para o manejo e a conservação florestal: Floresta Nacional do Tapajós (Beletera-Pará). PhD. These. Universidade Federal de Brasília, Brasília, $206 \mathrm{pp}$.

Mosseler, A., Major, J.E., Rajora, O.P., 2003. Old-growth red spruce forests as reservoirs of genetic diversity and reproductive fitness. Theor. Appl. Genet. 106, 931-937.

Murawski, D.A., Gunatilleke, I.A.U.N., Bawas, K.S., 1994. The effects of selective logging on inbreeding in Shorea megistophylla (Dipterocarpaceae) from Sri Lanka. Conserv. Biol. 8, 997-1002.

Nei, M., 1975. Molecular population genetics and evolution. In: Neuberger, A., Tatum, E.L. (Eds.), Frontier of Biology, vol. 40. Elsevier, New York.

Obayashi, K., Kalasa, J., Armesto, J.J., Collins, S.L., 2002. The ecological concept of disturbance and its expression at various hierarchical levels. Int. J. Plant Sci. 163, 151-158.

Pascarella, J.B., 1992. Notes on flowering phenology, nectar robbing and pollination of Symphonia globulifera L.F. (Clusiaceae) in a lowland rain forest in Costa Rica. Brenesia 38, 83-86.

Phillips, P.D., De Azevedo, C.P., Degen, B., van Gardingen, P.R., Thompson, I.S., Silva, J.N.M., 2004. An individual-based spatially explicit simulation model for strategic forest management planning in the eastern Amazon. Ecol. Model. 173, 335-354.

Rajora, O.P., Pluhar, S.A., 2003. Genetic diversity impacts of forest fire, forest harvesting, and alternative reforestation practices in black spruce (Picea mariana). Theor. Appl. Genet. 106, 1203-1212.

Rajora, O.P., Rahman, M.H., Buchert, G.P., Dancik, B.P., 2000. Microsatellite DNA analysis of genetic effects of harvesting in old-growth eastern white pine (Pinus strobus) in Ontario, Canada. Mol. Ecol. 9, 339-348.

Ritland, K., Jain, S., 1981. A model for the estimation of outcrossing rate and gene frequencies using independent loci. Heredity 47, 35-52.

SAS Institute Inc., 1999. SAS Procedures Guide. Version 8 (TSMO) SAS Institute Inc., Cary, NC.

Savolainen, O., Kärkkäinen, K., 1992. Effect of forest management on gene pools. New For. 6, 329-345.

Schulze, M., Vidal, E., Grogan, J., Zweede, J., Zarin, D., 2005. Madeiras nobres em perigo. Ciência Hoje 36, 66-69.

Silva, M.B., 2005. Aspectos ecológicos e genéticos de Bagassa guianensis Aubl. (Moraceae): um enfoque para o manejo florestal sustentado da espécies. PhD These. Belém, UFP, 165 pp.

Silva, J.N.M., de Carvalho, J.O.P., Lopes, J.C.A., Almeida, B.F., Costa, D.H.M., de Oliveira, L.C., Vanclay, J.K., Skovsgaard, J.P., 1995. Growth and yield of a tropical rain forest in the Brazilian Amazon 13 years after logging. For. Ecol. Manage. 71, 267-274.

Silva, J.N.M., de Carvalho, J.O.P., Lopes, J.C.A., de Oliveira, R.P., de Oliveira, L.C., 1996. Growth and yield studies in the Tapajós region, Central Brazilian Amazon. Commonw. For. Rev. 75, 325-329.

Sist, P., Fimbel, R., Sheil, D., Nasi, R., Chevallier, M.-H., 2003. Towards sustainable management of mixed dipterocarp forest of South-East Asia: moving beyond minimum diameter cutting limits. Environ. Conserv. 30, 364-374.

Smouse, P.E., Dyer, R.J., Westfall, R.D., Sork, V.L., 2001. Two-generation analysis of pollen flow across a landscape. I. Male gamete heterogeneity among females. Evolution 55, 260-271.

van Gardingen, P.R., Valle, D., Thompson, I., 2006. Evaluation of yield regulation options for primary forest in Tapajós National Forest, Brazil. For. Ecol. Manage. 231, 184-194.

Vison, C.C., Amaral, A.C., Sampaio, I., Ciampi, A.Y., 2005. Characterization and isolation of DNA microsatellite primers for the tropical tree, Symphonia globulifera Linn. Mol. Ecol. Not. 5, 202-204.

Young, A.G., Boyle, T.J., 2000. Forest fragmentation. In: Young, A.G., Boshier, D., Boyle, T.J. (Eds.), Forest Conservation Genetics: Principles and Practice. CSIRO Publishing, Melbourne, pp. 123-134. 